\title{
Conversion of $\mathrm{Fe}-\mathrm{NH}_{2}$ to $\mathrm{Fe}-\mathrm{N}_{2}$ with release of $\mathrm{NH}_{3}$
}

\author{
John S. Anderson, Marc-Etienne Moret, and Jonas C. Peters \\ Division of Chemistry and Chemical Engineering, California Institute of Technology, Pasadena, \\ California 91125, United States
}

\begin{abstract}
Tris(phosphine)borane ligated $\mathrm{Fe}(\mathrm{I})$ centers featuring $\mathrm{N}_{2} \mathrm{H}_{4}, \mathrm{NH}_{3}, \mathrm{NH}_{2}$, and $\mathrm{OH}$ ligands are described. Conversion of $\mathrm{Fe}-\mathrm{NH}_{2}$ to $\mathrm{Fe}-\mathrm{NH}_{3}{ }^{+}$by addition of acid, and subsequent reductive release of $\mathrm{NH}_{3}$ to generate $\mathrm{Fe}-\mathrm{N}_{2}$, is demonstrated. This sequence models the final steps of proposed Fe-mediated nitrogen fixation pathways. The five-coordinate trigonal bipyramidal complexes described are unusual in that they adopt $S=3 / 2$ ground states and are prepared from a four-coordinate, $S=3 / 2$ trigonal pyramidal precursor.
\end{abstract}

Due the structural and mechanistic complexity of biological nitrogen fixation ${ }^{1}$ a variety of mechanisms have been proposed that invoke either Mo or $\mathrm{Fe}$ as the likely active site for $\mathrm{N}_{2}$ binding and reduction. Fe- $\mathrm{NH}_{2}$ is an intermediate common to both limiting mechanisms (i.e., distal vs. alternating) being considered for Fe-mediated $\mathrm{N}_{2}$ fixation scenarios at the FeMo-cofactor. ${ }^{2,3}$ Such a species could form via reductive protonation of the nitride intermediate of a distal scheme (i.e., $\mathrm{Fe}(\mathrm{N}) \rightarrow \mathrm{Fe}(\mathrm{NH}) \rightarrow \mathrm{Fe}\left(\mathrm{NH}_{2}\right) \rightarrow \mathrm{Fe}\left(\mathrm{NH}_{3}\right)$ ), or by reductive protonation of a hydrazine intermediate of an alternating scheme (i.e., $\mathrm{Fe}\left(\mathrm{NH}_{2-}\right.$ $\left.\left.\mathrm{NH}_{2}\right) \rightarrow \mathrm{Fe}\left(\mathrm{NH}_{2}\right)+\mathrm{NH}_{3}\right)$. In the latter context, detection of an EPR active $\mathrm{Fe}-\mathrm{NH}_{2}$ or possibly $\mathrm{Fe}-\mathrm{NH}_{3}$ common intermediate has been proposed under reducing conditions at the FeMo-cofactor from substrates including $\mathrm{N}_{2}, \mathrm{~N}_{2} \mathrm{H}_{4}$, and $\mathrm{MeN}=\mathrm{NH} .{ }^{3 \mathrm{a}}$

One key to realizing a catalytic cycle in either limiting scenario concerns the regeneration of $\mathrm{Fe}-\mathrm{N}_{2}$ from $\mathrm{Fe}-\mathrm{NH}_{2}$ with concurrent release of $\mathrm{NH}_{3}{ }^{4}$ While there have been recent synthetic reports demonstrating $\mathrm{NH}_{3}$ generation from $\mathrm{Fe}(\mathrm{N})$ nitride model complexes, these studies have not provided information about the plausible downstream $\mathrm{Fe}\left(\mathrm{NH}_{\mathrm{X}}\right)(\mathrm{X}=1,2,3)$ intermediates en route to $\mathrm{NH}_{3}$ release, nor have these systems illustrated the feasibility of regeneration of Fe- $\mathrm{N}_{2} .{ }^{5}$ Herein we describe a terminal, $S=3 / 2 \mathrm{Fe}-\mathrm{NH}_{2}$ complex for which the stepwise conversion to $\mathrm{Fe}-\mathrm{NH}_{3}$, and then to $\mathrm{Fe}-\mathrm{N}_{2}$ along with concomitant release of $\mathrm{NH}_{3}$, is demonstrated (eqns 1 and 2).

$$
\begin{aligned}
\mathrm{Fe}-\mathrm{NH}_{2}+\mathrm{H}^{+} & \rightarrow \mathrm{Fe}-\mathrm{NH}_{3^{+}} \\
\mathrm{Fe}-\mathrm{NH}_{3}+\mathrm{e}^{-}+\mathrm{N}_{2} & \rightarrow \mathrm{Fe}-\mathrm{N}_{2}+\mathrm{NH}_{3}
\end{aligned}
$$

Addition of methyllithium to (TPB) $\mathrm{FeBr}^{6}$ affords the corresponding methyl complex (TPB)FeMe (1) in high yield (Scheme 1). Protonation of $\mathbf{1}$ by $\mathrm{HBAr}_{4} \cdot 2 \mathrm{Et}_{2} \mathrm{O}\left(\mathrm{BAr}_{4^{-}}=\right.$

Corresponding Author, jpeters@ caltech.edu.

ASSOCIATED CONTENT

Supporting Information. Detailed experimental and spectroscopic data. This material is available free of charge via the Internet at http://pubs.acs.org. 
$\left.\mathrm{B}\left(3,5-\mathrm{C}_{6} \mathrm{H}_{3}\left(\mathrm{CF}_{3}\right)_{2}\right)_{4}-\right)$ in a cold ethereal solution releases methane to yield [(TPB)Fe] $\left[\mathrm{BAr}_{4}{ }_{4}\right](\mathbf{2})$ which serves as a useful synthon with a vacant coordination site.

XRD data were obtained for $\mathbf{1}$ and $\mathbf{2}$ (Figure 1). The geometry of $\mathbf{1}$ is pseudo trigonal bipyramidal about Fe with an Fe-C bond length of 2.083(10) $\AA$ and an Fe-B bond length of 2.522 (2) A. In the solid state 2 possesses a four-coordinate distorted trigonal pyramidal geometry with no close contacts in the apical site trans to boron, making this complex coordinatively unsaturated. Additionally, there is one wide P-Fe-P angle of $136^{\circ}$. The origin of this large angle is not clear, but a possible explanation is increased back-bonding from a relatively electron rich $\mathrm{Fe}$ center into the phosphine ligands that would arise from this distortion.

The Fe-B distance in $\mathbf{2}(2.217(2) \AA)$ is markedly shorter than that in (TPB)FeBr (2.459(5) $\AA$ ), which is noteworthy because one might expect the loss of an anionic $\sigma$-donor ligand to reduce the Lewis basicity of the metal and thus weaken the Fe-B bond. For example, the AuB distance in (TPB) AuCl (2.318 $\AA$ ) lengthens upon chloride abstraction to $2.448 \AA$ in [(TPB)Au $]^{+} .{ }^{7}$ To explain this difference we note that the boron center in four-coordinate $\mathbf{2}$ is less pyramidalized $\left(\Sigma(\mathrm{C}-\mathrm{B}-\mathrm{C})=347.3^{\circ}\right)$ than that in five-coordinate $(\mathrm{TPB}) \mathrm{FeBr}(\Sigma(\mathrm{C}-\mathrm{B}$ $-\mathrm{C})=341.2^{\circ}$ ), pointing to a weak interaction despite the short distance. These observations suggest that the geometry of $\mathbf{2}$ might be best understood as derived from a planar threecoordinate $\mathrm{Fe}(\mathrm{I})$ center distorted towards a T-shaped geometry, ${ }^{8}$ the unusually short $\mathrm{Fe}-\mathrm{B}$ distance being due largely to the constraints imposed by the ligand cage structure. This interpretation is consistent with a computational model study: the DFT (B3LYP/6-31G(d)) optimized geometry of the hypothetical complex $\left[\left(\mathrm{Me}_{2} \mathrm{PhP}\right)_{3} \mathrm{Fe}\right]^{+}$(see SI for details) exhibits a planar geometry with P-Fe-P angles of $134.8^{\circ}, 113.1^{\circ}$, and $111.7^{\circ}$, very close to those measured for $[(\mathrm{TPB}) \mathrm{Fe}]^{+}\left(137.5^{\circ}, 113.2^{\circ}, 109.1^{\circ}\right)$.

When considering the bonding of the $(\mathrm{Fe}-\mathrm{B})^{7}$ subunit of $\mathbf{2}$ to estimate the best oxidation state and valence assignment, two limiting scenarios present themselves: $\mathrm{Fe}(\mathrm{III}) / \mathrm{B}(\mathrm{I})$ and $\mathrm{Fe}(\mathrm{I}) / \mathrm{B}(\mathrm{III})$. The structural data and computations for 2 are suggestive of a weak Fe-B interaction and indicate that this species is better regarded as $\mathrm{Fe}(\mathrm{I}) / \mathrm{B}(\mathrm{III})$ rather than $\mathrm{Fe}(\mathrm{III}) /$ B(I). Calculations indicate that a small amount of spin density resides on the Batom of 2 (SI) and suggest some contribution from an $\mathrm{Fe}(\mathrm{II}) / \mathrm{B}$ (II) resonance form may also be relevant. The rest of the complexes 3-6 presented herein possess significantly longer, and presumably weaker, Fe-B interactions (vide infra) and are hence also better classified as $\mathrm{Fe}(\mathrm{I})$ species. Additional spectroscopic studies (e.g., XAS and Mössbauer) will help to better map the Fe$\mathrm{B}$ bonding interaction across the variable $\mathrm{Fe}-\mathrm{B}$ distances and also the spin states of the complexes. These studies would thereby help to determine the value and limitation of classically derived oxidation/valence assignments for boratranes of these types. ${ }^{9}$

Solutions of 2 are orange in $\mathrm{Et}_{2} \mathrm{O}$ and pale yellow-green in THF. Titration of THF into an ethereal solution of $\mathbf{2}$ results in a distinct change in the UV-vis spectrum consistent with weak THF binding. Addition of an excess of $\mathrm{N}_{2} \mathrm{H}_{4}$ to an ethereal solution of 2 results in a slight lightening of the orange color of the solution to afford [(TPB)Fe $\left.\left(\mathrm{N}_{2} \mathrm{H}_{4}\right)\right]\left[\mathrm{BAr} \mathrm{F}_{4}\right](\mathbf{3})$ in $89 \%$ yield. Complex 3 shows a paramagnetically shifted ${ }^{1} \mathrm{H}$ NMR spectrum indicative of an $S=3 / 2$ Fe center that is corroborated by a room temperature solution magnetic moment, $\mu_{\text {eff }}$, of $3.5 \mu_{\mathrm{B}}$. Crystals of $\mathbf{3}$ were obtained and XRD analysis (Figure $2 \mathrm{~A}$ ) indicates a distorted trigonal bipyramidal geometry. The Fe-N distance of 2.205(2) $\AA$ is unusually long ( $2.14 \AA$ is the average quaternary N-Fe distance in the Cambridge Structural Database) reflecting its unusual quartet spin state.

Complex $\mathbf{3}$ is stable to vacuum, but solutions decompose cleanly at room temperature over hours to form the cationic ammonia complex $\left[(\mathrm{TPB}) \mathrm{Fe}\left(\mathrm{NH}_{3}\right)\right]\left[\mathrm{BAr}_{4}{ }_{4}\right], \mathbf{4}$, which was 
assigned by comparison of its ${ }^{1} \mathrm{H}$ NMR spectrum with an independently prepared sample formed by the addition of $\mathrm{NH}_{3}$ to the cation $\mathbf{2}$. Analysis of additional degradation products shows only $\mathrm{NH}_{3}$ and trace $\mathrm{H}_{2}$ (SI). The assignment of $\mathbf{4}$ as an ammonia adduct was confirmed by XRD analysis (Figure 2B). Like 3, complex 4 shows a long Fe-N distance of 2.280(3) $\AA$ in the solid state. The complexes $\mathbf{2}, \mathbf{3}$ and $\mathbf{4}$ are unusual by virtue of their $S=3 / 2$ spin states and underscore the utility of local 3-fold symmetry with respect to stabilizing high spin states at iron, even in the presence of strong-field phosphine ligands.

Addition of $\mathrm{NaNH}_{2}$ to the cation 2 affords the terminal amide, (TPB)Fe- $\mathrm{NH}_{2}$ (5) in ca. $85 \%$ non-isolated yield by ${ }^{1} \mathrm{H}$ NMR integration. The XRD structure of 5 (Figure 2C) shows an overall geometry similar to that observed in $\mathbf{1}, \mathbf{3}$, and $\mathbf{4}$. Of interest is the short Fe-N distance of $1.918(3) \AA$ by comparison to 4 (2.280(3) $\AA$ ). The amide hydrogens were located in the difference map and indicate a nearly planar geometry about $\mathrm{N}$ (with the sum of the angles around $\mathrm{N}$ being $355^{\circ}$ ).

While the XRD data set of $\mathbf{5}$ is of high quality, we were concerned about the difficulty in distinguishing an $\mathrm{Fe}-\mathrm{NH}_{2}$ group from a potentially disordered $\mathrm{Fe}-\mathrm{OH}$ moiety. We therefore independently characterized the hydroxo complex, (TPB)Fe-OH (6) (Scheme 2), which possesses a geometry similar to that observed in $\mathbf{5}$ with an Fe-B distance of 2.4438(9) $\AA$ and an Fe-O distance of 1.8916(7) A. Despite the structural similarity between $\mathbf{5}$ and $\mathbf{6}$, different spectral signatures in both their ${ }^{1} \mathrm{H}$ NMR and EPR (Figure 3) spectra allow for facile distinction between them. Like $\mathbf{2 , 3}$, and $\mathbf{4}$, both $\mathbf{5}$ and $\mathbf{6}$ are $S=3 / 2$.

Low-temperature EPR data (Figure 3) have been obtained on complexes 1-6. All complexes show features shifted to large g-values consistent with quartet Fe species. ${ }^{10}$ This assignment is verified by the solution magnetic moments obtained for these complexes. Variable temperature solid-state SQUID magnetic data for complexes 2-5 (SI) also establish quartet spin state assignments and display no evidence for spin-crossover phenomena. These data show a drop in magnetic moment in the range $50-70 \mathrm{~K}$ for all compounds studied. We propose that this effect is due to a large zero-field splitting in these species, which is consistent with Fe centers in related geometries. ${ }^{11}$ Simulations with zero-field splitting of $10-20 \mathrm{~cm}^{-1}$ provide reasonable fits to the data.

Parent amide complexes of first row transition metals are rare. ${ }^{12}$ Noteworthy precedent for related terminal $\mathrm{M}-\mathrm{NH}_{2}$ species includes two square planar nickel complexes ${ }^{12 \mathrm{a}, \mathrm{d}}$ and one octahedral and diamagnetic iron complex, $(\mathrm{dmpe})_{2} \mathrm{Fe}(\mathrm{H}) \mathrm{NH}_{2} \cdot{ }^{12 \mathrm{e}} \mathrm{In}$ addition to their different coordination numbers, geometries, and spin-states, $(\mathrm{dmpe})_{2} \mathrm{Fe}(\mathrm{H})\left(\mathrm{NH}_{2}\right)$ and $\mathbf{5}$ show a distinct difference at the Fe- $\mathrm{NH}_{2}$ subunit. Six-coordinate $(\mathrm{dmpe}){ }_{2} \mathrm{Fe}(\mathrm{H})\left(\mathrm{NH}_{2}\right)$ is an 18 -electron species without $\pi$-donation from the amide ligand, which is pyramidalized as a result. By contrast, five-coordinate $\mathbf{5}$ accommodates $\boldsymbol{\pi}$-bonding from the amide. This is borne out in its much shorter Fe-N distance (1.918(3) ̊ for 5 vs $2.068 \AA$ for (dmpe $)_{2} \mathrm{Fe}(\mathrm{H})$ $\left(\mathrm{NH}_{2}\right)$ ), and also its comparative planarity (the sum of the angles around $\mathrm{N}$ is $355^{\circ}$ for 5 vs $325^{\circ}$ for $\left.(\mathrm{dmpe})_{2} \mathrm{Fe}(\mathrm{H})\left(\mathrm{NH}_{2}\right)\right)$.

With the terminal amide $\mathbf{5}$ in hand we explored its suitability as a precursor to the previously reported $\mathrm{N}_{2}$ complex (TPB)Fe( $\mathrm{N}_{2}$ ) via release of $\mathrm{NH}_{3}$ and hence explored reduction/ protonation vs protonation/reduction sequences as a means of effecting overall $\mathrm{H}$-atom transfer to the $\mathrm{Fe}-\mathrm{NH}_{2}$ unit. Attempts to carry out the one-electron reduction of $\mathbf{5}$ were not informative. For example, electrochemical studies of $\mathbf{5}$ in THF failed to show any reversible reduction waves, but the addition of harsh reductants (e.g., $t \mathrm{BuLi}$ ) to $\mathbf{5}$ did show small amounts of (TPB)Fe $\left(\mathrm{N}_{2}\right)$ in the product profile. A more tractable conversion sequence utilized protonation followed by chemical reduction. Thus, the addition of $\mathrm{HBAr}_{4} \cdot 2 \mathrm{Et}_{2} \mathrm{O}$ to 5 at low temperature $\left(-35^{\circ} \mathrm{C}\right)$ rapidly generates the cationic ammonia adduct 4 . The 
conversion is quantitative as determined by ${ }^{1} \mathrm{H}$ NMR spectroscopy, and $\mathbf{4}$ can be isolated in ca. $90 \%$ yield from the solution. Subsequent exposure of $\mathbf{4}$ to one equiv of $\mathrm{KC}_{8}$ under an atmosphere of $\mathrm{N}_{2}$ releases $\mathrm{NH}_{3}$ and generates the (TPB)FeN $\mathrm{N}_{2}$ complex in similarly high yield.

In summary, an unusual series of $S=3 / 2$ iron complexes featuring terminally bonded $\mathrm{N}_{2} \mathrm{H}_{4}$, $\mathrm{NH}_{3}, \mathrm{NH}_{2}$, and $\mathrm{OH}$ functionalities has been thoroughly characterized. These complexes are supported by a tris(phosphine)borane ligand and are best described as Fe(I) species that feature weak Fe-B bonding, though other resonance contributions to the bonding scheme warrant additional consideration. The $\mathrm{Fe}-\mathrm{NH}_{2}$ species faithfully models the reductive replacement of the terminal $\mathrm{NH}_{2}$ group by $\mathrm{N}_{2}$ with concomitant release of $\mathrm{NH}_{3}$, lending credence to such a pathway as mechanistically feasible in Fe-mediated $\mathrm{N}_{2}$ reduction schemes. Because spectroscopic detection of a common $\mathrm{Fe}-\mathrm{NH}_{2}$ or $\mathrm{Fe}-\mathrm{NH}_{3}$ intermediate under reductive turnover of the FeMo-cofactor has been recently proposed, ${ }^{3}$ EPR active model complexes of the types described here should prove useful for comparative purposes.

\section{Supplementary Material}

Refer to Web version on PubMed Central for supplementary material.

\section{Acknowledgments}

This work was supported by the NIH (GM 070757) and the Gordon and Betty Moore Foundation, and through the NSF via a GRFP award to JSA. M.-E. M. acknowledges a Fellow-ship for Advanced Researchers from the Swiss National Science Foundation. Larry Henling and Dr. Jens Kaiser are thanked for their assistance with X-ray crystallography and Dr. Angelo DiBilio for his assistance with EPR measurements. We acknowledge the Gordon and Betty Moore Foundation, the Beckman Institute, and the Sanofi-Aventis BRP at Caltech for their generous support of the Molecular Observatory at Caltech. SSRL is operated for the DOE and supported by its Office of Biological and Environmental Research, and by the NIH, NIGMS (including P41GM103393) and the NCRR (P41RR001209).

\section{REFERENCES}

1. (a) Einsle O, Tezcan FA, Andrade SLA, Schmid B, Yoshida M, Howard JB, Rees DC. Science. 2002; 297:1696-1700. [PubMed: 12215645] (b) Spatzal T, Aksoyoglu M, Zhang LM, Andrade SLA, Schleicher E, Weber S, Rees DC, Einsle O. Science. 2011; 334 940-940.

2. (a) Crossland JL, Tyler DR. Coord. Chem. Rev. 2010; 254:1883-1894.(b) Field LD, Li HL, Dalgarno SJ, Turner P. Chem. Commun. 2008:1680-1682.(c) Hazari N. Chem. Soc. Rev. 2010; 39:4044-4056. [PubMed: 20571678] (d) Vela J, Stoian S, Flaschenriem CJ, Münck E, Holland PL. J. Am. Chem. Soc. 2004; 126:4522-4523. [PubMed: 15070362]

3. (a) Lukoyanov D, Dikanov SA, Yang Z-Y, Barney BM, Samoilova RI, Narasimhulu KV, Dean DR, Seefeldt LC, Hoffman BM. J. Am. Chem. Soc. 2011; 133:11655-11664. [PubMed: 21744838] (b) Seefeldt LC, Hoffman BM, Dean DR. Annu. Rev. Biochem. 2009; 78:701-722. [PubMed: 19489731]

4. Lee Y, Mankad NP, Peters JC. Nat. Chem. 2010; 2:558-565. [PubMed: 20571574]

5. (a) Betley TA, Peters JC. J. Am. Chem. Soc. 2004; 126:6252-6254. [PubMed: 15149221] (b) Scepaniak JJ, Fulton MD, Bontchev RP, Duesler EN, Kirk ML, Smith JM. J. Am. Chem. Soc. 2008; 130:10515-10517. [PubMed: 18630913] (c) Scepaniak JJ, Vogel CS, Khusniyarov MM, Heinemann FW, Meyer K, Smith JM. Science. 2011; 331:1049-1052. [PubMed: 21350172] (d) Scepaniak JJ, Young JA, Bontchev RP, Smith JM. Angew. Chem. Int. Ed. 2009; 48:3158-3160.

6. Moret M-E, Peters JC. Angew. Chem. Int. Ed. 2011; 50:2063-2067.

7. Sircoglou M, Bontemps S, Bouhadir G, Saffon N, Miqueu K, Gu W, Mercy M, Chen C-H, Foxman BM, Maron L, Ozerov OV, Bourissou D. J. Am. Chem. Soc. 2008; 130:16729-16738. [PubMed: 19554696] 
8. A stable T-shaped,three-coordinate Fe(I) is known: Ingleson MJ, Fullmer BC, Buschhorn DT, Fan H, Pink M, Huffman JC, Caulton KG. Inorg. Chem. 2008; 47:407-409. [PubMed: 18154331]

9. (a) Amgoune A, Bourissou D. Chem. Comm. 2011; 47:859-871. [PubMed: 21103473] (b) Hill AF, Owen GR, White AJP, Williams DJ. Angew. Chem. Int. Ed. 1999; 38:2759-2761.(c) Pang K, Quan SM, Parkin G. Chem. Comm. 2006:5015-5017. [PubMed: 17146512]

10. Stoian SA, Yu Y, Smith JM, Holland PL, Bominaar EL, Munck E. Inorg. Chem. 2005; 44:49154922. [PubMed: 15998018]

11. Harman WH, Harris TD, Freedman DE, Fong H, Chang A, Rinehart JD, Ozarowski A, Sougrati MT, Grandjean F, Long GJ, Long JR, Chang CJ. J. Am. Chem. Soc. 2010; 132:18115-18126. [PubMed: 21141856]

12. (a) Adhikari D, Mossin S, Basuli F, Dible BR, Chipara M, Fan H, Huffman JC, Meyer K, Mindiola DJ. Inorg. Chem. 2008; 47:10479-10490. [PubMed: 18855380] (b) Brady E, Telford JR, Mitchell G, Lukens W. Acta Cryst. C. 1995; 51:558-560.(c) Redshaw C, Wilkinson G, Hussain-Bates B, Hursthouse MB. J. Chem. Soc. Dalton. 1992:1803-1811.(d) Cámpora J, Palma P, del Río D, Conejo MM, Álvarez E. Organometallics. 2004; 23:5653-5655.(e) Fox DJ, Bergman RG. J. Am. Chem. Soc. 2003; 125:8984-8985. [PubMed: 15369333] (f) Sofield CD, Walter MD, Andersen RA. Acta Cryst. C. 2004; 60:465-466. 

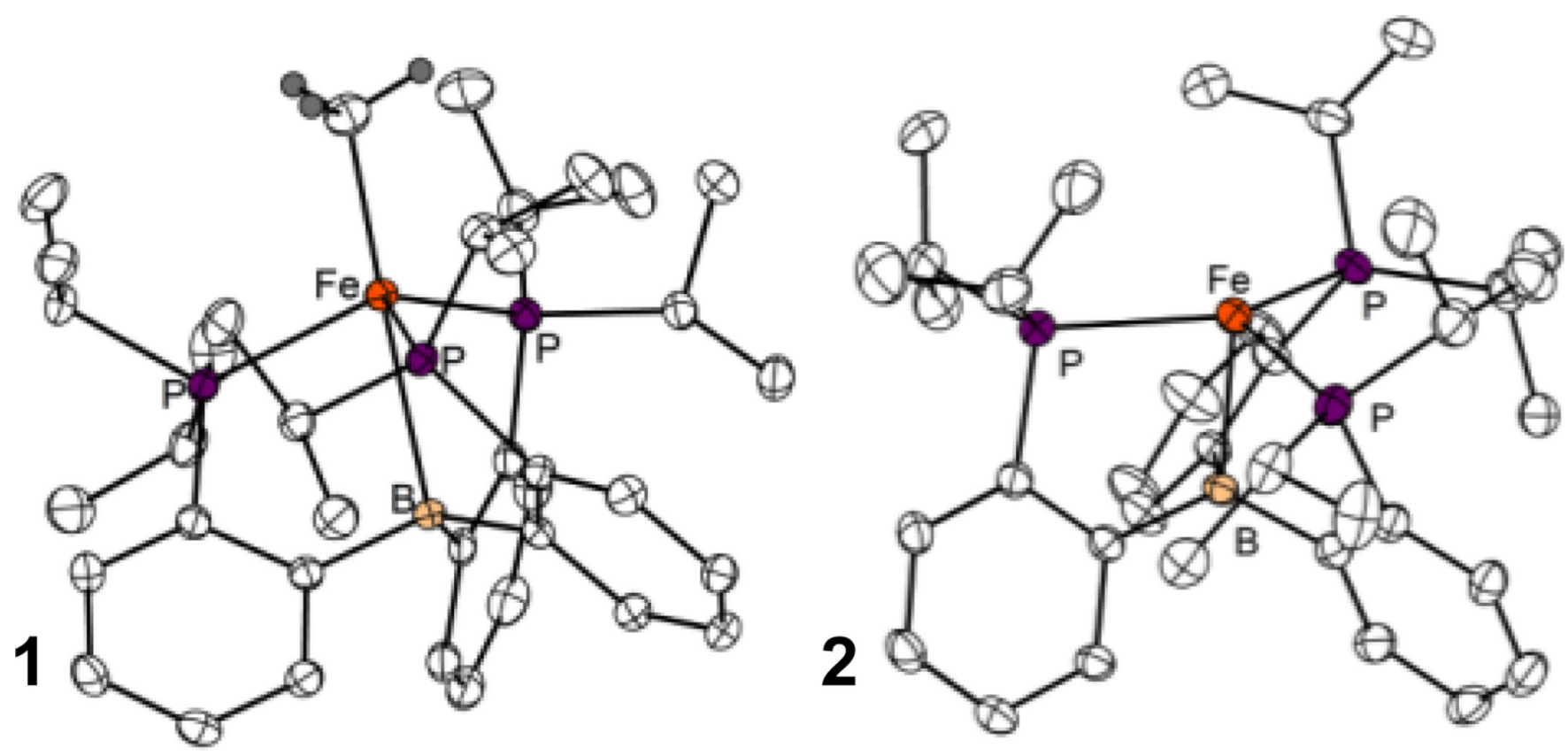

Figure 1.

X-Ray Diffraction (XRD) structures of complexes 1 (A) and 2 (B) with hydrogen atoms and counterion (for B) omitted for clarity. See Table 1 for selected bond lengths and angles. 


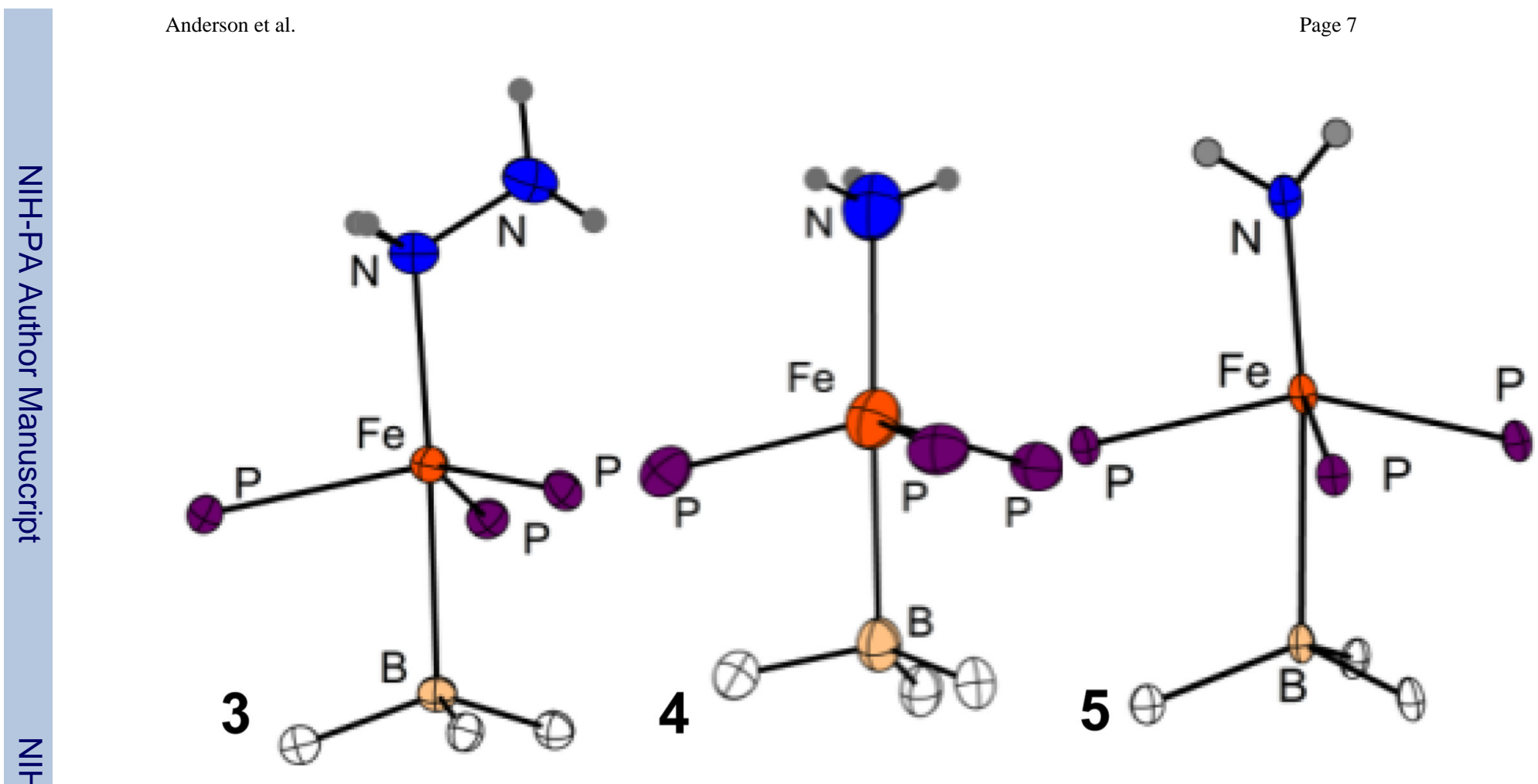

Figure 2.

XRD structures of the cores of complexes 3 (A), 4 (B), and $\mathbf{5}$ (C). See Table 1 for selected distances and angles. 


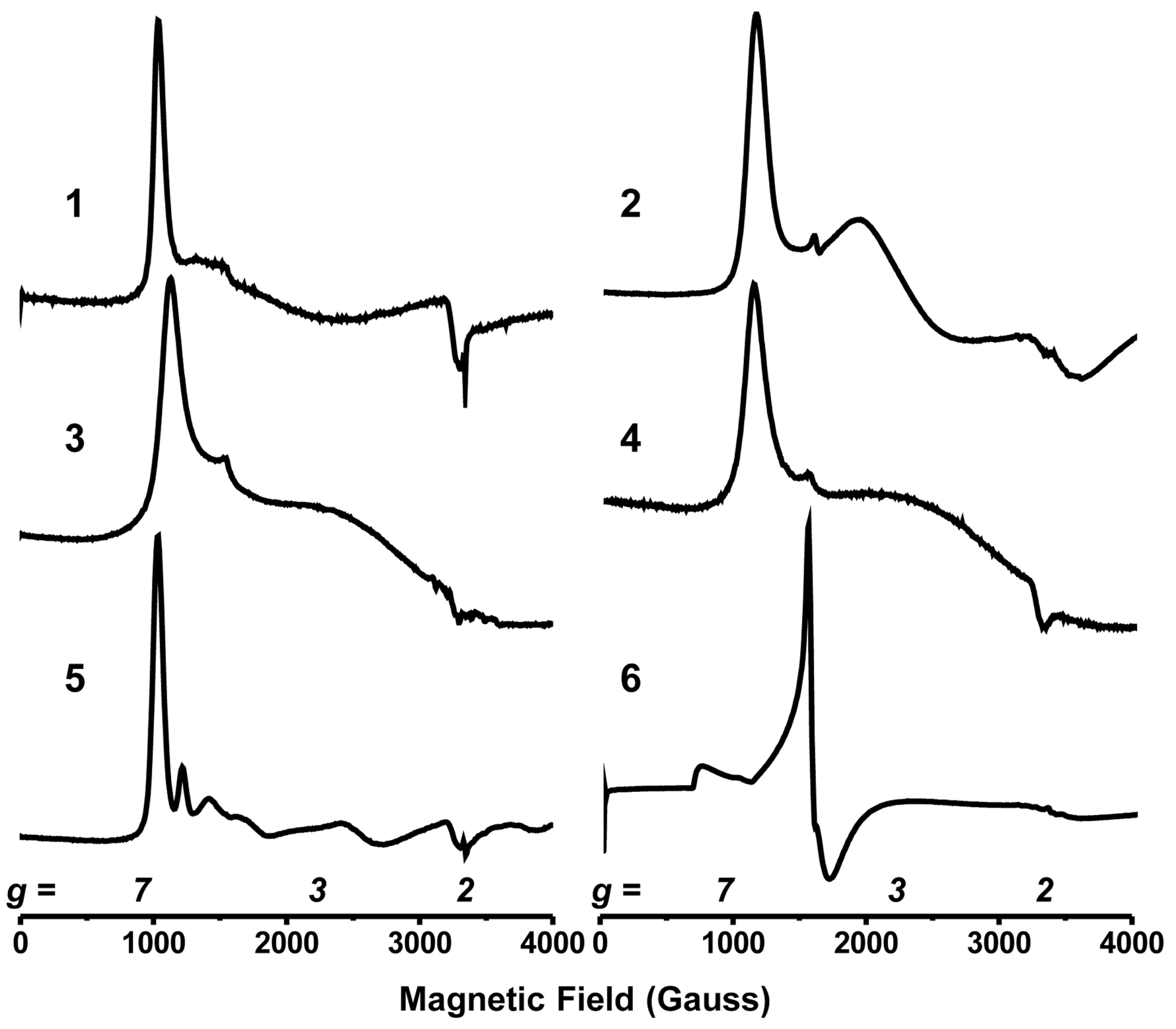

Figure 3.

$\mathrm{X}$-Band EPR spectra for complexes 1-6. Conditions for 1: Toluene, $8 \mathrm{~K} ; \mathbf{2}: 2: 1$

Toluene:Et ${ }_{2} \mathrm{O}, 10 \mathrm{~K}$ 3: 2-MeTHF, $10 \mathrm{~K}$; 4: 2-MeTHF, $10 \mathrm{~K}$; 5: 2-MeTHF, $10 \mathrm{~K}$; 6: Toluene, $10 \mathrm{~K}$. 


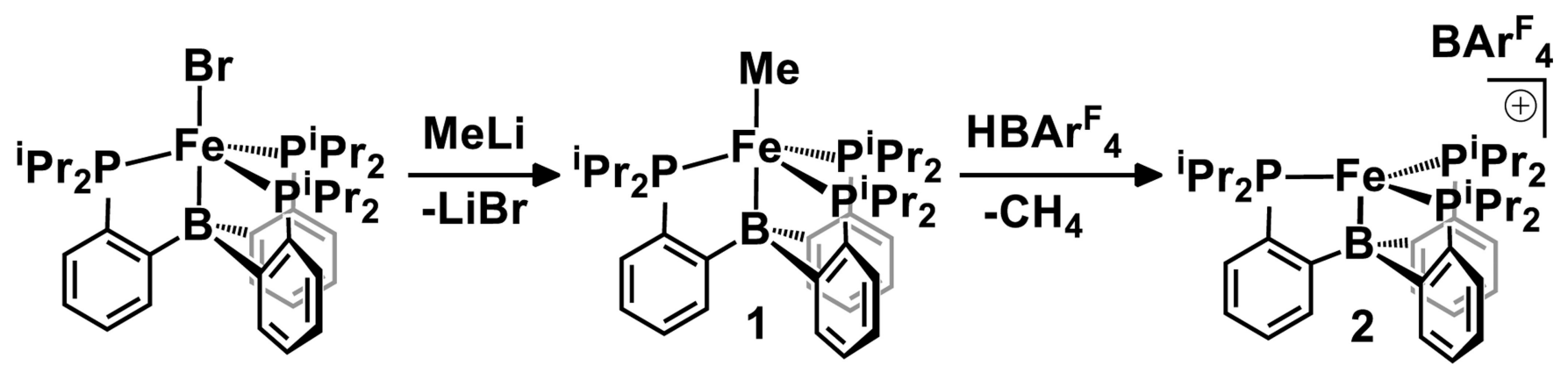

SCHEME 1. 


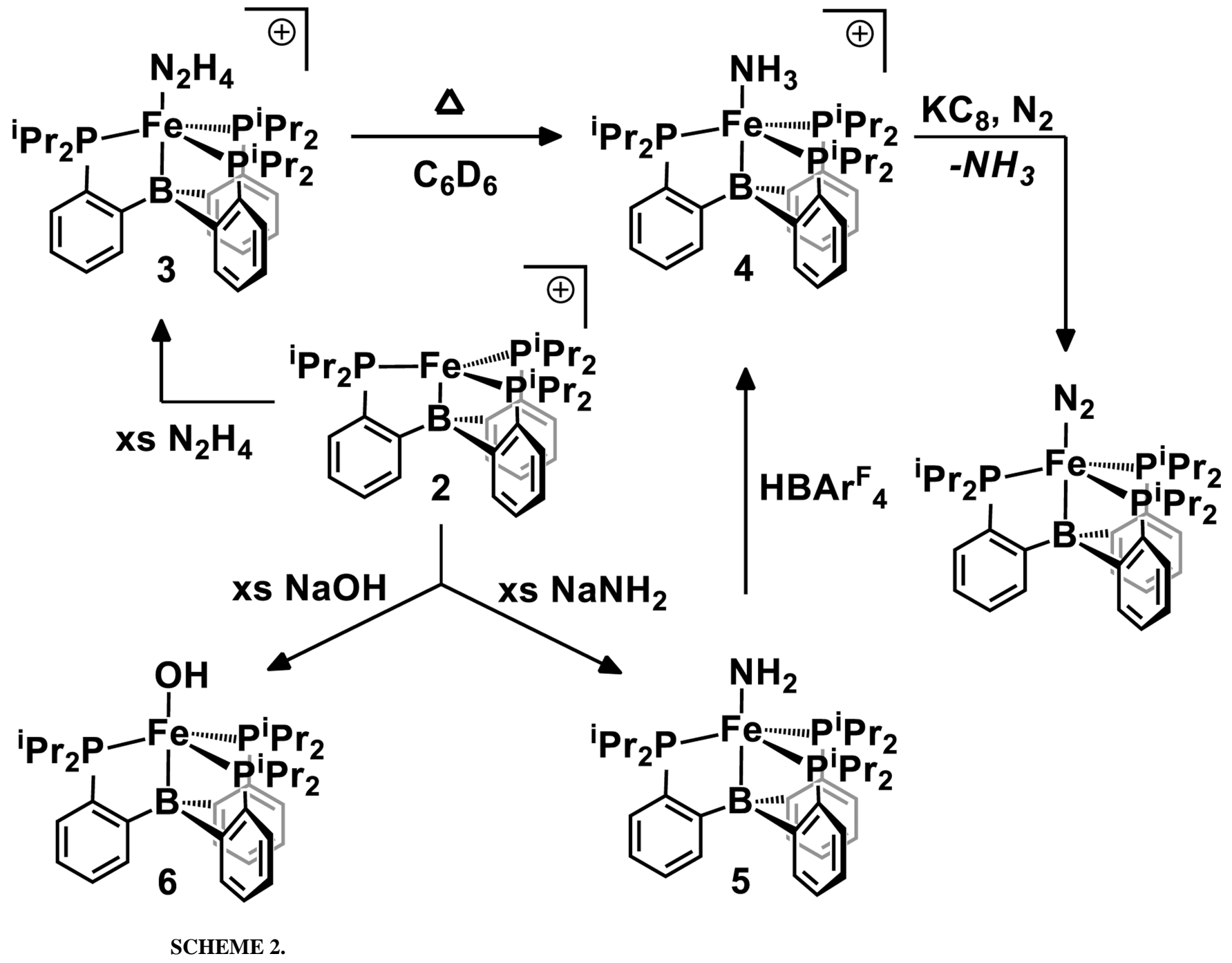




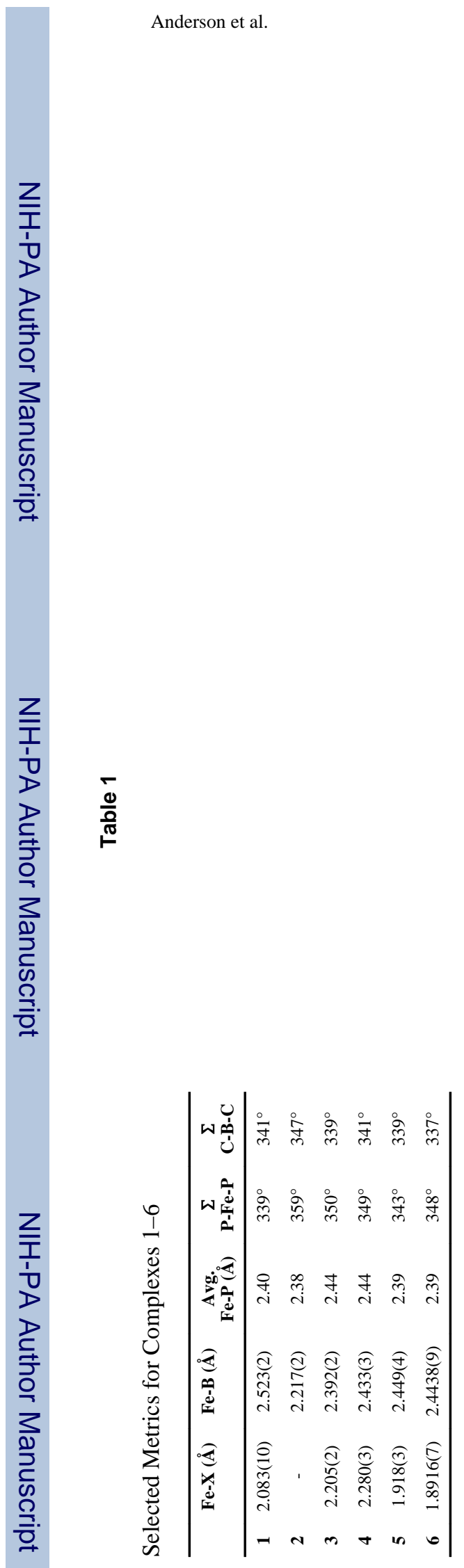

$J$ Am Chem Soc. Author manuscript; available in PMC 2014 January 16. 